\title{
Study of the Correlations among Some Parameters of the Oxidative Status, Gelatinases, and Their Inhibitors in a Group of Subjects with Metabolic Syndrome
}

\author{
E. Hopps, R. Lo Presti, M. Montana, B. Canino, M. R. Averna, and G. Caimi \\ Dipartimento Biomedico di Medicina Interna e Specialistica, Università degli Studi di Palermo, Via del Vespro 129, \\ 90100 Palermo, Italy
}

Correspondence should be addressed to E. Hopps; eugenia.hopps@unipa.it

Received 15 April 2014; Revised 26 June 2014; Accepted 27 June 2014; Published 10 July 2014

Academic Editor: Fábio Santos de Lira

Copyright (C) 2014 E. Hopps et al. This is an open access article distributed under the Creative Commons Attribution License, which permits unrestricted use, distribution, and reproduction in any medium, provided the original work is properly cited.

\begin{abstract}
Our aim was to examine some parameters of oxidative status, gelatinases, and their inhibitors and to evaluate their interrelationships in subjects with metabolic syndrome (MS). We enrolled 65 MS subjects, subdivided according to the presence or not of diabetes mellitus. We examined lipid peroxidation (expressed as thiobarbituric acid reacting substances, TBARS), protein oxidation (expressed as carbonyl groups), nitric oxide metabolites $\left(\mathrm{NO}_{x}\right.$ ), total antioxidant status (TAS), MMP-2, MMP-9, TIMP-1, and TIMP2. We found that MS subjects, diabetics and nondiabetics, showed an increase in TBARS, PC, and $\mathrm{NO}_{x}$. A significant decrease in TAS was observed only in nondiabetic MS subjects in comparison with diabetic MS subjects. We observed increased concentrations of MMP-2, MMP-9, TIMP-1, and TIMP-2, higher in diabetic subjects. Our data showed a positive correlation between TAS and MMP-2, TAS and MMP-9, and TAS and MMP-9/TIMP-1 and a negative correlation between TBARS and MMP-2 in diabetic MS subjects in the entire group. In MS subjects a prooxidant status and increased levels of gelatinases and their inhibitors are evident although the correlations between oxidative stress and MMPs or TIMPs are controversial and need further investigation.
\end{abstract}

\section{Introduction}

Today the metabolic syndrome (MS) is considered a public health problem [1]. As it is known, obesity and MS are associated with a low-grade of chronic systemic inflammation, reflected by an increase in circulating leukocytes and by elevated levels of proinflammatory cytokines $[2,3]$ that contributes to the development of insulin-resistance and atherosclerosis [4] via the activation of nuclear factor-kB pathway [5]. The alterations of the vascular wall start from the endothelial dysfunction and oxidative stress and also an altered matrix metalloproteinases (MMPs) expressions contribute to the consequent remodelling of the basal membrane.

In the last years, we have been interested in the evaluation of the redox balance [6-10] and of the MMPs profile $[11,12]$ in MS. MMPs are related to atherosclerotic disease and to cardiovascular morbidity and mortality [13-18]; these are endopeptidases responsible for the degradation of several extracellular matrix proteins, such as collagen, laminin, gelatin, and fibronectin [19] which are produced into the vascular wall and are denominated in relation to their target (collagenase, gelatinase, stromelysin, or matrilysin). Gelatinases A and B (MMP-2 and -9) are involved in the vascular remodelling that precedes the atherosclerosis development and also in its worse outcomes [20, 21]. MMP-9 has been discovered in older atherosclerotic lesions [22] and is responsible for fibrosis, matrix degradation, and angiogenesis resulting in plaque instability and rupture [22, 23], while MMP-2 has been correlated with a more stable plaque and with rare haemorrhages [24]. The regulation of MMPs production and activity is complex. Some MMPs (MMP-2) are constitutively expressed on cell surface, while others (MMP-9) are stored in secretory granules and are inducible by exogenous stimuli, such as cytokines, growth factors, and cell-matrix contacts $[19,20]$. MMPs are synthesized as precursors (pro-MMP) and they must be activated, to expose the catalytic domain with the $\mathrm{Zn}^{2+}$-binding site, by several proteases, such as plasmin, thrombin, chimase, and membrane-type MMP (MT-MMPs) 
$[19,25]$, or by S-glutathiolation, S-nitrosylation, and phosphorylation reactions [23].

MMPs and oxidative stress seem to be strongly correlated in subjects with high cardiovascular risk [26-30] and this link has been demonstrated in several experimental models [3134]. Peroxynitrite $\left(\mathrm{ONOO}^{-}\right)$activates some MMPs via the Sglutathiolation $[31,34]$ but, at higher concentrations, can lead to the inactivation of MMP-2 [34]. Also hydrogen peroxide $\left(\mathrm{H}_{2} \mathrm{O}_{2}\right)$ activates MMP-2 and promotes the expression of MMP-2 and MMP-9 in human venous endothelial cells [35]. Reactive oxygen species (ROS) can influence MMP transcription by means of the activation of the mitogen-activated protein kinase (MAPK), the inhibition of MAPK phosphatase, the inactivation of the histone deacetylase, and the recruitment of different chromatin remodelling factors [36]. MMPs activity is downregulated especially by the four tissue inhibitors of MMP (TIMPs): TIMP-1 inhibits MMP-1, MMP3, MMP-7, and MMP-9, TIMP-2 inhibits especially MMP-2, and TIMP- 3 can inhibit both the gelatinases, while TIMP-4 inhibits MT-1 MMP and MMP-2 activity [14].

In literature, there is no definite information regarding the effects of the oxidative stress on MMPs expression and activity in MS, even if classical cardiovascular risk factors, such as dyslipidemia and diabetes mellitus, increase the gelatinase levels via oxidative stress. In fact, the exposure of endothelial cells to oxidized LDL increases the levels of MT-1 MMP mRNA [37] and the treatment of monocytes-derived macrophages with oxidized HDL induces ROS production, release of TNF- $\alpha$, and an overexpression of MMP-2 and MMP-9 [38]. Also the effects of hyperglycemia on MMP-9 and MMP-2 activity in cultured cells are mediated by ROS [39-41].

Previously, we have focused on the oxidative status $[6,7$, 9] and the profile of gelatinases and tissue inhibitors [11, 12] in MS subjects. In this study, our aim was to evaluate, in a group of MS subjects, some parameters of the oxidative status, MMP-2, MMP-9, and their tissue inhibitors in order to investigate their statistical correlations.

\section{Materials and Methods}

We examined 65 subjects ( 41 men and 24 women; median age 51 yrs; interquartile range 12) selected from those referred to our observation from 2008 to 2011. MS was defined following the International Diabetes Federation (IDF) criteria [1]. The subjects were subsequently subdivided into diabetics (DMS) (22 men and 11 women; median age 59 yrs; IQR 7) and nondiabetics (NDMS) (19 men and 13 women; median age 46 yrs; IQR 9). The baseline characteristics of the two subgroups of DMS and NDMS subjects are described in Table 1. No subjects of both subgroups were taking antioxidants or practising exercise regularly. In the DMS subgroup, only 4 subjects were current smokers while 29 subjects were nonsmokers; in the NDMS subgroup, 11 subjects were current smokers while 21 were nonsmokers. Neither DMS nor NDMS subjects were heavy drinkers. In the subgroup of DMS subjects, diabetes had duration less than 5 years and was
TABLE 1: Medians (interquartile ranges) of the anthropometric profile, blood pressure values, and metabolic pattern in the whole group of MS subjects and in the two subgroups of MS subjects, respectively, with and without diabetes mellitus.

\begin{tabular}{|c|c|c|c|}
\hline & $\begin{array}{c}\text { All } \\
\text { MS patients }\end{array}$ & $\begin{array}{c}\text { Diabetic } \\
\text { MS patients }\end{array}$ & $\begin{array}{l}\text { Nondiabetic } \\
\text { MS patients }\end{array}$ \\
\hline $\begin{array}{l}\text { Waist circumference } \\
(\mathrm{cm})\end{array}$ & $105(14.5)$ & $113.0(16)$ & $100.5(8)^{\S}$ \\
\hline BMI $\left(\mathrm{Kg} / \mathrm{m}^{2}\right)$ & $31.95(4.71)$ & $33.2(4.4)$ & $31.4(4.2)$ \\
\hline SBP (mmHg) & $130(20)$ & $140(27.5)$ & $130(15)^{\#}$ \\
\hline DBP (mmHg) & $80(7.5)$ & $80(10)$ & $80(5)$ \\
\hline Glycaemia (mg/dL) & $101.5(40.5)$ & $130.5(80)$ & $91(13)^{\S}$ \\
\hline $\begin{array}{l}\text { Total cholesterol } \\
(\mathrm{mg} / \mathrm{dL})\end{array}$ & $207(74)$ & $186(50)$ & $227.5(60)^{\S}$ \\
\hline $\begin{array}{l}\text { HDL-cholesterol } \\
(\mathrm{mg} / \mathrm{dL})\end{array}$ & $40(15)$ & $41(17)$ & $38(11.5)$ \\
\hline $\begin{array}{l}\text { LDL-cholesterol } \\
(\mathrm{mg} / \mathrm{dL})\end{array}$ & $127.6(53.6)$ & $109(47.8)$ & $145(55.5)^{\S}$ \\
\hline $\begin{array}{l}\text { Triglyceridemia } \\
(\mathrm{mg} / \mathrm{dL})\end{array}$ & $180(84)$ & 159 (65) & $191.5(115)^{\#}$ \\
\hline $\begin{array}{l}\text { Triglyceridemia/HDL } \\
\text { cholesterol }\end{array}$ & $4.31(3.31)$ & $3.74(2.41)$ & $5.11(2.66)^{\#}$ \\
\hline
\end{tabular}

treated with diet and oral antidiabetic agents. In all participants, cholesterol and triglycerides were measured by standard enzymatic procedures, HDL-cholesterol after phosphotungstic acid/magnesium chloride precipitation and enzymatic determination of cholesterol, and LDL-cholesterol by the Friedewald formula.

In this group of MS subjects we examined on fasting venous blood the following.

(i) Lipid Peroxidation. The oxidation of polyunsaturated fatty acids was evaluated in plasma by detection of the TBARS, generated by peroxidative processes, which include lipid peroxides and MDA. The evaluation of TBARS was made by fluorimetry, using 1,1,3,3-tetramethoxypropane as standard [42].

(ii) Protein Oxidation. The protein carbonyl (PC) content was measured by an enzyme-linked immunosorbent assay (ELISA) kit (BioCell PC test kit, Enzo Life Sciences AG, Switzerland), which uses the classic PC reagent 2,4-dinitrophenylhydrazine (DNP). In brief, plasma samples were incubated with DNP, and then plasma proteins were nonspecifically adsorbed on an ELISA plate. Unconjugated DNP and nonprotein constituents were washed away. The adsorbed proteins were probed with biotinylated anti-DNP antibody, followed by streptavidin-linked horseradish peroxidase. A chromatin reagent was added, and the reaction was stopped by adding an acid solution. Absorbance for each well was measured at $450 \mathrm{~nm}$ and related to a standard curve prepared for serum albumin containing increasing proportions of hypochlorous acid-oxidized protein, calibrated colourimetrically. Total protein concentration in plasma 
TABLE 2: Medians (interquartile ranges) of gelatinase and inhibitor plasma concentrations in normal controls, in the whole group of MS patients, and in the two subgroups, respectively, with and without diabetes mellitus.

\begin{tabular}{lcccc}
\hline & Control subjects & $\begin{array}{c}\text { All } \\
\text { MS patients }\end{array}$ & $\begin{array}{c}\text { Diabetic } \\
\text { MS patients }\end{array}$ & $\begin{array}{c}\text { Nondiabetic } \\
\text { MS patients }\end{array}$ \\
\hline TBARS (nmol/mL) & $5.71(2.28)$ & $8.83(0.70)^{\ddagger}$ & $8.99(0.71)^{\ddagger}$ & $8.73(0.665)^{\ddagger}$ \\
PC (nmol/mg prot.) & $0.470(0.125)$ & $0.880(0.240)^{\ddagger}$ & $0.880(0.240)^{\ddagger}$ & $0.880(0.220)^{\ddagger}$ \\
TAS (mmol/L) & $0.910(0.330)$ & $0.880(0.300)$ & $0.910(0.150)$ & $0.720(0.395)^{\dagger \S}$ \\
NO $x(\mu \mathrm{mol} / \mathrm{L})$ & $28.05(24.65)$ & $74.80(26.52)^{\ddagger}$ & $77.10(24.20)^{\ddagger}$ & $67.70(43.92)^{\ddagger}$ \\
MMP-2 (ng/mL) & $29.19(6.07)$ & $44.50(10.46)^{\ddagger}$ & $47.84(10.76)^{\ddagger}$ & $39.69(9.75)^{\ddagger \S}$ \\
MMP-9 (ng/mL) & $53.17(6.57)$ & $105.6(36.15)^{\ddagger}$ & $127.3(28.7)^{\ddagger}$ & $91.50(11.61)^{\ddagger \S}$ \\
TIMP-1 (ng/mL) & $30.99(2.63)$ & $73.47(10.31)^{\ddagger}$ & $75.66(8.65)^{\ddagger}$ & $68.45(9.35)^{\ddagger \S}$ \\
TIMP-2 (ng/mL) & $87.27(6.28)$ & $98.77(14.38)^{\ddagger}$ & $99.79(12.86)^{\ddagger}$ & $95.21(15.32)^{\dagger \#}$ \\
MMP-2/TIMP-2 & $0.354(0.080)$ & $0.449(0.130)^{\ddagger}$ & $0.460(0.104)^{\ddagger}$ & $0.391(0.141)^{\dagger \#}$ \\
MMP-9/TIMP-1 & $1.720(0.150)$ & $1.480(0.345)$ & $1.658(0.339)$ & $1.347(0.298)^{\dagger \S}$ \\
\hline
\end{tabular}

${ }^{*} P<0.05,{ }^{\dagger} P<0.01$, and ${ }^{\ddagger} P<0.001$ versus control subjects (Mann-Whitney test).

${ }^{\#} P<0.01$ and ${ }^{\S} P<0.001$ versus diabetic MS patients.

samples was evaluated by the method of Lowry et al. [43].

(iii) Nitric Oxide Metabolites $\left(\mathrm{NO}_{x}\right)$. The NO production was evaluated by a micromethod, which measures the concentration of the $\mathrm{NO}$ metabolites, nitrite and nitrate $\left(\mathrm{NO}_{x}\right)$. In vivo $\mathrm{NO}$ has a very short half-life (less than $0.1 \mathrm{sec}$ ) and it is converted, through different biochemical pathways, into nitrite, which has a halflife of a few minutes, and the more stable nitrate. Plasma concentrations of nitrate are $90-99 \%$ of the total NO metabolites concentration, indicated as $\mathrm{NO}_{x}$. In the laboratory method adopted by us, nitrate was first converted into nitrite by a nitrate reductase; then nitrite was assessed by spectrophotometry after addition of the Griess reagent [44].

(iv) Total Antioxidant Status (TAS). TAS was obtained using an Assay kit (Calbiochem, La Jolla, CA, USA) which relies on the ability of plasma antioxidant substances to inhibit the oxidation of 2,2-azino-bis(3ethylbenzthiazoline sulfonic acid) (ABTS) to the radical cation $\mathrm{ABTS}^{\bullet+}$ by a peroxidase [45]. The radical concentration was measured by spectrophotometry.

(v) Gelatinases and Their Inhibitors. Plasma concentrations of gelatinases (MMP-2 and MMP-9) and their inhibitors (TIMP-1 and TIMP-2) were determined using, respectively, the Human MMP-2 ELISA and Human MMP-9 ELISA kit (Boster Biological Technology, Ltd.) and the Human TIMP-1 ELISA and Human TIMP-2 ELISA kit (Boster Biological Technology, Ltd.).

The same parameters have been examined in a group of 17 normal subjects ( 10 men and 7 women; median age 38 yrs; IQR 4), selected from the hospital staff. In this group of control subjects the basal glucose level was 89 (7) $\mathrm{mg} / \mathrm{dL}$, total cholesterol level was $200(40) \mathrm{mg} / \mathrm{dL}$, LDL-cholesterol was 142 (24) mg/dL, HDL-cholesterol was 46 (9) mg/dL, and triglycerides were $65(36) \mathrm{mg} / \mathrm{dL}$. The mean values of blood pressure in these subjects were $125(10) / 75$ (5) $\mathrm{mm} / \mathrm{Hg}$; BMI was 26 (4); waist circumference was $98(13) \mathrm{cm}$.

The Ethical Committee approved the study and each subject gave informed consent.

\section{Statistical Analysis}

The results were expressed as medians and interquartile ranges (IQR); the differences between MS subjects and normal controls as well as the differences between normal controls and subjects with MS subdivided in agreement with the presence or not of diabetes mellitus were estimated according to the Mann-Whitney test. The study of correlations was performed employing the Spearman rank correlation coefficient.

\section{Results}

Examining the baseline characteristics of subjects with MS we observed a significant decrease in waist circumference $(P<$ $0.001)$, systolic blood pressure $(P<0.05)$, and basal glucose level $(P<0.001)$ and a significant increase in total cholesterol $(P<0.001)$, LDL-cholesterol $(P<0.001)$, triglycerides $(P<$ $0.05)$, and triglycerides/HDL-cholesterol $(P<0.05)$ in NDMS subjects in comparison with DMS subjects (Table 1).

MS subjects showed an increase in lipid peroxidation, protein oxidation, and nitric oxide metabolites $\left(\mathrm{NO}_{x}\right)$ (Table 2). In the same group of MS subjects, we found an increase in MMP-2, MMP-9, TIMP-1, and TIMP-2 in comparison with normal subjects; we also observed an increase in MMP-2/TIMP-2 ratio, with no difference regarding MMP9/TIMP-1 ratio (Table 2). Subdividing the MS group in the two subgroups, we found that the increase in lipid peroxidation, protein oxidation, and $\mathrm{NO}_{x}$ was similar in DMS and NDMS subjects, while the decrease in TAS was significantly evident only in NDMS subjects, in comparison with normal and DMS subjects (Table 2). We observed also that the plasma concentrations of MMP-2, MMP-9, TIMP-1, and TIMP-2 
were significantly increased in the two subgroups in comparison with normal subjects, but in MS subjects with DM the values were higher than in nondiabetics (Table 2). The MMP-2/TIMP-2 ratio was significantly increased in the two subgroups in comparison with normal subjects although its value was lower in NDMS than in DMS subjects (Table 2). The MMP-9/TIMP-1 ratio instead was significantly decreased in MS subjects without DM, not only in comparison with normal subjects but also in comparison with DMS subjects (Table 2).

In normal controls, as well as in the two subgroups of subjects with MS, no statistical correlation was observed among age, parameters of oxidative status, gelatinases, and tissue inhibitors. Examining the linear regression among TBARS, gelatinases, and their inhibitors, we found a negative correlation between TBARS and MMP-2 in DMS subjects (Table 4). No correlation among carbonyl groups, gelatinases, and their inhibitors was evident (Tables 3, 4, and 5) and no relationship among $\mathrm{NO}_{x}$, gelatinases, and their inhibitors was observed (Tables 3, 4, and 5). A positive correlation between TAS and MMP-2, TAS and MMP-9, and TAS and MMP-9/TIMP-1 ratio in the entire group of MS subjects was found (Table 3 ).

\section{Discussion}

The results of this research confirm all the data previously published by us $[7,9,10,12]$ : the parameters of the oxidative stress distinguish DMS from NDMS subjects and are altered even in middle-aged MS subjects [10]. Also the gelatinases and their inhibitors discriminate DMS from NDMS subjects and in fact their means were significantly higher in MS diabetic subjects.

Our goal was in particular the evaluation of the statistical correlations between the parameters of the oxidative status and the gelatinases and their tissue inhibitors in MS.

It has been observed that ox-LDLs upregulate MMP-9 expression and reduce TIMP-1 expression in monocytederived macrophages [46] and that MDA, which is included in TBARS, is correlated with the MMP-9 activity in subjects with acute coronary syndrome [27]. In this study however the TBARS that reflects lipid peroxidation was negatively correlated with MMP-2 only in DMS subjects.

No correlation was observed among protein oxidation, gelatinases, and their inhibitors, although in experimental models [35] a significant correlation between carbonyl groups and MMP-9 has been described.

We noted especially a positive correlation between TAS and MMP-2, between TAS and MMP-9, and between TAS and MMP-9/TIMP-1 ratio in the entire group of MS subjects. As it is known, TAS includes enzymatic antioxidants (superoxide dismutase, catalase, and glutathione peroxidase) and nonenzymatic antioxidants (uric acid, ascorbic acid, bilirubin, vitamin E, and carotenoids). The examination of the literature data regarding the correlations between antioxidants and MMPs profile shows controversial aspects. In fact, MMP9 plasma levels are negatively associated with provitamin A carotenoids in a general population [47] while, in experimental models, the deficiency of vitamin A seems to be
TABLE 3: Correlations between oxidative parameters and gelatinases in all MS subjects.

\begin{tabular}{lcccc}
\hline & $\begin{array}{c}\text { Versus } \\
\text { TBARS }\end{array}$ & $\begin{array}{c}\text { Versus } \\
\text { PC }\end{array}$ & $\begin{array}{c}\text { Versus } \\
\text { TAS }\end{array}$ & $\begin{array}{c}\text { Versus } \\
\mathrm{NO}_{x}\end{array}$ \\
\hline MMP-2 & -0.162 & -0.043 & $0.255^{\#}$ & -0.077 \\
MMP-9 & 0.176 & -0.025 & $0.315^{\#}$ & 0.075 \\
TIMP-1 & 0.094 & -0.067 & -0.052 & -0.012 \\
TIMP-2 & 0.126 & -0.199 & 0.067 & 0.071 \\
MMP-2/TIMP-2 & -0.206 & 0.035 & 0.196 & -0.100 \\
MMP-9/TIMP-1 & 0.133 & -0.017 & $0.320^{\S}$ & 0.097 \\
\hline
\end{tabular}

${ }^{\#} P<0.05 ;{ }^{\circledR} P<0.01$ (Spearman's rank correlation).

TABLE 4: Correlations between oxidative parameters and gelatinases in diabetic MS subjects.

\begin{tabular}{lcccc}
\hline & Versus & Versus & Versus & Versus \\
& TBARS & PC & TAS & $\mathrm{NO}_{x}$ \\
\hline MMP-2 & $-0.363^{\#}$ & -0.240 & -0.235 & -0.144 \\
MMP-9 & 0.180 & -0.144 & -0.057 & 0.295 \\
TIMP-1 & 0.002 & 0.000 & -0.287 & 0.079 \\
TIMP-2 & 0.224 & -0.266 & 0.148 & 0.287 \\
MMP-2/TIMP-2 & -0.283 & -0.100 & -0.263 & -0.149 \\
MMP-9/TIMP-1 & 0.167 & -0.136 & 0.028 & 0.216 \\
\hline
\end{tabular}

${ }^{\#} P<0.05$ (Spearman's rank correlation).

TABLE 5: Correlations between oxidative parameters and gelatinases in nondiabetic MS subjects.

\begin{tabular}{lcccc}
\hline & $\begin{array}{c}\text { Versus } \\
\text { TBARS }\end{array}$ & $\begin{array}{c}\text { Versus } \\
\text { PC }\end{array}$ & $\begin{array}{c}\text { Versus } \\
\text { TAS }\end{array}$ & $\begin{array}{c}\text { Versus } \\
\mathrm{NO}_{x}\end{array}$ \\
\hline MMP-2 & -0.346 & 0.097 & 0.207 & -0.167 \\
MMP-9 & -0.041 & -0.021 & 0.236 & -0.163 \\
TIMP-1 & 0.055 & -0.174 & -0.289 & -0.167 \\
TIMP-2 & -0.067 & -0.154 & -0.193 & -0.140 \\
MMP-2/TIMP-2 & -0.280 & 0.195 & 0.316 & -0.077 \\
MMP-9/TIMP-1 & -0.104 & 0.084 & 0.317 & -0.065 \\
\hline
\end{tabular}

responsible for a gelatinase decrease without any variations of TIMPs [48]. In subjects with acute stroke the infusion of uric acid induced a decrease of total and active MMP-9 levels [49] and the treatment with antioxidants (polyethylene glycolsuperoxide dismutase and $\mathrm{N}$-acetyl-L-cysteine) reduces the MMP-9 activity in plasma and in aortic tissue homogenates of experimental models of diabetes mellitus [39] and the use of tempol (a ROS scavenger) reduces MMP-2 levels and its activity in aortic rings of animal models of renovascular hypertension [50]. Even in experimental models of oxidative stress (obtained with the depletion of glutathione), taurine inhibits MMP-2 activation in cardiac tissues [51]. Differently, the treatment with retinoic acid increases significantly MMP9 but not MMP-2 [48] and lutein, a carotenoid, enhances MMP-9 synthesis in animal models [52]. Therefore, all these studies do not clarify how in subjects with MS the TAS could be positively related to the gelatinases and their tissue inhibitors and then all these data need further investigation. 
With regard to the behaviour of $\mathrm{NO}_{x}$, its increase in MS is related especially to a nitric oxide overproduction by macrophages, in which the NO synthase activation is caused by cytokines, such as TNF- $\alpha$ and IL-1 $\beta$ [53-55] that are able to induce also MMPs expression [56-58]. In this study, no statistical correlation was observed among $\mathrm{NO}_{x}$, gelatinases and their inhibitors in the whole group and in the two subgroups of MS subjects. Keeping in mind that NO production and gelatinases expression are induced by the same cytokines that are increased in MS [59], the inflammatory state could be the link between oxidative stress and MMPs. In addition, it must be considered that, during an inflammatory response, leukocyte infiltration through basal membranes is only possible if these cells produce enzymes that can degrade the extracellular matrix so MMPs, as well as ROS, are crucial effector molecules of inflammatory cells, which play a sure role in atherosclerosis and other chronic inflammatory and metabolic diseases [60].

\section{Conclusions}

There are several data regarding the influence of the oxidative status on the gelatinases and their tissue inhibitors. In this preliminary study concerning a small group of MS subjects, we observed a significant alteration of all these parameters, although from the statistical analysis of the data it is difficult to clarify how the oxidative stress could influence the plasma levels of the gelatinases and their inhibitors. Further investigation seems to be necessary, considering the impact of MS on cardiovascular morbidity and mortality and especially the opportunity of specific therapeutic strategies.

\section{Conflict of Interests}

The authors declare that there is no conflict of interests regarding the publication of this paper.

\section{References}

[1] K. G. M. M. Alberti, P. Zimmet, and J. Shaw, "The metabolic syndrome-a new worldwide definition," The Lancet, vol. 366, no. 9491, pp. 1059-1062, 2005.

[2] G. R. Romeo, J. Lee, and S. E. Shoelson, "Metabolic syndrome, insulin resistance, and roles of inflammation: mechanisms and therapeutic targets," Arteriosclerosis, Thrombosis, and Vascular Biology, vol. 32, no. 8, pp. 1771-1776, 2012.

[3] M. D. DeBoer, "Obesity, systemic inflammation, and increased risk for cardiovascular disease and diabetes among adolescents: a need for screening tools to target interventions," Nutrition, vol. 29, no. 2, pp. 379-386, 2013.

[4] J. I. Odegaard and A. Chawla, "Pleiotropic actions of insulin resistance and inflammation in metabolic homeostasis," Science, vol. 339, no. 6116, pp. 172-177, 2013.

[5] E. Fuentes, F. Fuentes, G. Vilahur, L. Badimon, and I. Palomo, "Mechanisms of chronic state of inflammation as mediators that link obese adipose tissue and metabolic syndrome," Mediators of Inflammation, vol. 2013, Article ID 136584, 11 pages, 2013.
[6] E. Hopps, D. Noto, G. Caimi, and M. R. Averna, "A novel component of the metabolic syndrome: the oxidative stress," Nutrition, Metabolism and Cardiovascular Diseases, vol. 20, no. 1, pp. 72-77, 2010.

[7] G. Caimi, E. Hopps, M. Montana et al., "Evaluation of nitric oxide metabolites in a group of subjects with metabolic syndrome," Diabetes and Metabolic Syndrome: Clinical Research and Reviews, vol. 6, no. 3, pp. 132-135, 2012.

[8] E. Hopps and G. Caimi, "Protein oxidation in metabolic syndrome," Clinical \& Investigative Medicine, vol. 36, no. 1, pp. E1E8, 2013.

[9] G. Caimi, E. Hopps, D. Noto et al., "Protein oxidation in a group of subjects with metabolic syndrome," Diabetes and Metabolic Syndrome: Clinical Research and Reviews, vol. 7, no. 1, pp. 38-41, 2013.

[10] E. Hopps, R. Lo Presti, D. Noto, M. R. Averna, and G. Caimi, "Oxidative status in nondiabetic middle-aged subjects with metabolic syndrome: preliminary data," Nutrition, Metabolism and Cardiovascular Diseases, vol. 23, no. 5, pp. el7-e18, 2013.

[11] E. Hopps and G. Caimi, "Matrix metalloproteinases in metabolic syndrome," European Journal of Internal Medicine, vol. 23, no. 2, pp. 99-104, 2012.

[12] E. Hopps, R. Lo Presti, M. Montana, D. Noto, M. R. Averna, and G. Caimi, "gelatinases and their tissue inhibitors in a group of subjects with metabolic syndrome," Journal of Investigative Medicine, vol. 61, pp. 978-983, 2013.

[13] M. Flamant, S. Placier, C. Dubroca et al., "Role of matrix metalloproteinases in early hypertensive vascular remodeling," Hypertension, vol. 50, no. 1, pp. 212-218, 2007.

[14] P. R. Nagareddy, P. S. Rajput, H. Vasudevan et al., "Inhibition of matrix metalloproteinase-2 improves endothelial function and prevents hypertension in insulin-resistant rats," British Journal of Pharmacology, vol. 165, no. 3, pp. 705-715, 2012.

[15] M. M. Castro, J. E. Tanus-Santos, and R. F. Gerlach, "Matrix metalloproteinases: targets for doxycycline to prevent the vascular alterations of hypertension," Pharmacological Research, vol. 64, no. 6, pp. 567-572, 2011.

[16] F. M. Khezheva, N. A. Mazur, and V. P. Masenko, "Metalloproteinase activity of the blood in patients with arterial hypertension with paroxysmal form of atrial fibrillation," Kardiologiia, vol. 47, no. 12, pp. 10-14, 2007.

[17] M. H. Tayebjee, S. K. Nadar, R. J. MacFadyen, and G. Y. H. Lip, "Tissue inhibitor of metalloproteinase-1 and matrix metalloproteinase-9 levels in patients with hypertension: relationship to tissue Doppler indices of diastolic relaxation," American Journal of Hypertension, vol. 17, no. 9, pp. 770-774, 2004.

[18] X. Gai, Z. Zhang, Y. Liang et al., "MMP-2 and TIMP-2 gene polymorphisms and susceptibility to atrial fibrillation in Chinese Han patients with hypertensive heart disease," Clinica Chimica Acta, vol. 411, no. 9-10, pp. 719-724, 2010.

[19] C. Amălinei, I. D. Căruntu, and R. A. Bălan, "Biology of metalloproteinases," Romanian Journal of Morphology and Embryology, vol. 48, no. 4, pp. 323-334, 2007.

[20] D. Bourboulia and W. G. Stetler-Stevenson, "Matrix metalloproteinases (MMPs) and tissue inhibitors of metalloproteinases (TIMPs): positive and negative regulators in tumor cell adhesion," Seminars in Cancer Biology, vol. 20, no. 3, pp. 161-168, 2010.

[21] A. Jaiswal, A. Chhabra, U. Malhotra, S. Kohli, and V. Rani, "Comparative analysis of human matrix metalloproteinases: emerging therapeutic targets in diseases," Bioinformation, vol. 6, no. 1, pp. 23-30, 2011. 
[22] P. Liu, M. Sun, and S. Sader, "Matrix metalloproteinases in cardiovascular disease," Canadian Journal of Cardiology, vol. 22, pp. 25B-30B, 2006.

[23] J. Hansson, R. S. Vasan, J. Ärnlöv et al., "Biomarkers of extracellular matrix metabolism (MMP-9 and TIMP-1) and risk of stroke, myocardial infarction, and cause-specific mortality: cohort study," PLoS ONE, vol. 6, no. 1, Article ID e16185, 2011.

[24] R. Dhingra, M. J. Pencina, P. Schrader et al., "Relations of matrix remodeling biomarkers to blood pressure progression and incidence of hypertension in the community," Circulation, vol. 119, no. 8, pp. 1101-1107, 2009.

[25] Z. Al-Hamodi, I. S. Ismail, R. Saif-Ali, K. A. Ahmed, and S. Muniandy, "Association of plasminogen activator inhibitor-1 and tissue plasminogen activator with type 2 diabetes and metabolic syndrome in Malaysian subjects," Cardiovascular Diabetology, vol. 10, article R23, 2011.

[26] M. R. Hayden, J. R. Sowers, and S. C. Tyagi, "The central role of vascular extracellular matrix and basement membrane remodeling in metabolic syndrome and type 2 diabetes: the matrix preloaded," Cardiovascular Diabetology, vol. 4, article 9, 2005.

[27] A. Bittner, H. Alcaíno, P. F. Castro et al., "Matrix metalloproteinase- 9 activity is associated to oxidative stress in patients with acute coronary syndrome," International Journal of Cardiology, vol. 143, no. 1, pp. 98-100, 2010.

[28] P. J. Kelly, J. D. Morrow, M. Ning et al., "Oxidative stress and matrix metalloproteinase-9 in acute ischemic stroke: the Biomarker Evaluation for Antioxidant Therapies in Stroke (BEATStroke) study," Stroke, vol. 39, no. 1, pp. 100-104, 2008.

[29] K. Kameda, T. Matsunaga, N. Abe et al., "Correlation of oxidative stress with activity of matrix metalloproteinase in patients with coronary artery disease. Possible role for left ventricular remodelling," European Heart Journal, vol. 24, no. 24, pp. 21802185, 2003.

[30] K. Pawlak, J. Tankiewicz, M. Mysliwiec, and D. Pawlak, "Systemic levels of MMP2/TIMP2 and cardiovascular risk in CAPD patients," Nephron: Clinical Practice, vol. 115, no. 4, pp. c251c258, 2010.

[31] A. D. Kandasamy, A. K. Chow, M. A. Ali, and R. Schulz, "Matrix metalloproteinase-2 and myocardial oxidative stress injury: beyond the matrix," Cardiovascular Research, vol. 85, no. 3, pp. 413-423, 2010.

[32] D. J. Brown, B. Lin, M. Chwa, S. R. Atilano, D. W. Kim, and M. C. Kenney, "Elements of the nitric oxide pathway can degrade TIMP-1 and increase gelatinase activity," Molecular Vision, vol. 10, pp. 281-288, 2004.

[33] S. Donnini, M. Monti, R. Roncone et al., "Peroxynitrite inactivates human-tissue inhibitor of metalloproteinase-4," FEBS Letters, vol. 582, no. 7, pp. 1135-1140, 2008.

[34] S. Viappiani, A. C. Nicolescu, A. Holt et al., "Activation and modulation of $72 \mathrm{kDa}$ matrix metalloproteinase- 2 by peroxynitrite and glutathione," Biochemical Pharmacology, vol. 77, no. 5, pp. 826-834, 2009.

[35] T. Koken, F. Gursoy, and A. Kahraman, "Long-term alcohol consumption increases pro-matrix metalloproteinase-9 Levels via oxidative stress," Journal of Medical Toxicology, vol. 6, no. 2, pp. 126-130, 2010.

[36] S. Kar, S. Subbaram, P. M. Carrico, and J. A. Melendez, "Redoxcontrol of matrix metalloproteinase-1: a critical link between free radicals, matrix remodeling and degenerative disease," Respiratory Physiology and Neurobiology, vol. 174, no. 3, pp. 299306, 2010 .
[37] T. B. Rajavashisth, J. K. Liao, Z. S. Galis et al., "Inflammatory cytokines and oxidized low density lipoproteins increase endothelial cell expression of membrane type 1-matrix metalloproteinase," The Journal of Biological Chemistry, vol. 274, no. 17, pp. 11924-11929, 1999.

[38] V. S. Soumyarani and N. Jayakumari, "Oxidatively modified high density lipoprotein promotes inflammatory response in human monocytes-macrophages by enhanced production of ROS, TNF- $\alpha$, MMP-9, and MMP-2," Molecular and Cellular Biochemistry, vol. 366, no. 1-2, pp. 277-285, 2012.

[39] S. Uemura, H. Matsushita, W. Li et al., "Diabetes mellitus enhances vascular matrix metalloproteinase activity role of oxidative stress," Circulation Research, vol. 88, no. 12, pp. 12911298, 2001.

[40] F. M. Ho, S. H. Liu, W. W. Lin, and C. S. Liau, "Opposite effects of high glucose on MMP-2 and TIMP-2 in human endothelial cells," Journal of Cellular Biochemistry, vol. 101, no. 2, pp. 442450, 2007.

[41] A. K. Death, E. J. Fisher, K. C. Y. McGrath, and D. K. Yue, "High glucose alters matrix metalloproteinase expression in two key vascular cells: potential impact on atherosclerosis in diabetes," Atherosclerosis, vol. 168, no. 2, pp. 263-269, 2003.

[42] C. Di Massimo, P. Scarpelli, N. D. Lorenzo, G. Caimi, F. D. Orio, and M. G. T. Ciancarelli, "Impaired plasma nitric oxide availability and extracellular superoxide dismutase activity in healthy humans with advancing age," Life Sciences, vol. 78, no. 11, pp. 1163-1167, 2006.

[43] O. H. Lowry, N. J. Rosebrough, and A. L. Farr, "Protein measurement with the Folin phenol reagent," The Journal of Biological Chemistry, vol. 193, no. 1, pp. 265-275, 1951.

[44] R. W. Nims, J. F. Darbyshire, J. E. Saavedra et al., "Colorimetric methods for the determination of nitric oxide concentration in neutral aqueous solutions," Methods, vol. 7, no. 1, pp. 48-54, 1995.

[45] N. J. Miller, C. Rice-Evans, M. J. Davies, V. Gopinathan, and A. Milner, "A novel method for measuring antioxidant capacity and its application to monitoring the antioxidant status in premature neonates," Clinical Science, vol. 84, no. 4, pp. 407-412, 1993.

[46] X. P. Xu, S. R. Meisel, J. M. Ong et al., "Oxidized low-density lipoprotein regulates matrix metalloproteinase- 9 and its tissue inhibitor in human monocyte-derived macrophages," Circulation, vol. 99, no. 8, pp. 993-998, 1999.

[47] M. Rydén, P. Garvin, M. Kristenson, P. Leanderson, J. Ernerudh, and L. Jonasson, "Provitamin a carotenoids are independently associated with matrix metalloproteinase- 9 in plasma samples from a general population," Journal of Internal Medicine, vol. 272, no. 4, pp. 371-384, 2012.

[48] G. Esteban-Pretel, M. P. Marín, J. Renau-Piqueras, Y. Sado, T. Barber, and J. Timoneda, "Vitamin A deficiency disturbs collagen IV and laminin composition and decreases matrix metalloproteinase concentrations in rat lung. Partial reversibility by retinoic acid," The Journal of Nutritional Biochemistry, vol. 24, no. 1, pp. 137-145, 2013.

[49] S. Amaro, V. Obach, A. Cervera et al., "Course of matrix metalloproteinase-9 isoforms after the administration of uric acid in patients with acute stroke : a proof-of-concept study," Journal of Neurology, vol. 256, no. 4, pp. 651-656, 2009.

[50] M. M. Castro, E. Rizzi, G. J. Rodrigues et al., "Antioxidant treatment reduces matrix metalloproteinase-2-induced vascular changes in renovascular hypertension," Free Radical Biology and Medicine, vol. 46, no. 9, pp. 1298-1307, 2009. 
[51] G. Sevin, G. Ozsarlak-Sozer, D. Keles et al., "Taurine inhibits increased MMP-2 expression in a model of oxidative stress induced by glutathione depletion in rabbit heart," European Journal of Pharmacology, vol. 706, no. 1-3, pp. 98-106, 2013.

[52] H. M. Lo, C. L. Chen, C. M. Yang et al., "The carotenoid lutein enhances matrix metalloproteinase- 9 production and phagocytosis through intracellular ROS generation and ERK1/2, p38 MAPK, and RAR $\beta$ activation in murine macrophages," Journal of Leukocyte Biology, vol. 93, no. 5, pp. 723-735, 2013.

[53] S. Moncada, R. M. J. Palmer, and E. A. Higgs, "Nitric oxide: physiology, pathophysiology, and pharmacology," Pharmacological Reviews, vol. 43, no. 2, pp. 109-142, 1991.

[54] U. Förstermann, H. Kleinert, I. Gath, P. Schwarz, E. I. Closs, and N. J. Dun, "Expression and expressional control of nitric oxide synthases in various cell types," Advances in Pharmacology, vol. 34, pp. 171-186, 1995.

[55] J. B. Weinberg, "Nitric oxide production and nitric oxide synthase type 2 expression by human mononuclear phagocytes: a review," Molecular Medicine, vol. 4, no. 9, pp. 557-591, 1998.

[56] E. E. J. M. Creemers, J. P. M. Cleutjens, J. F. M. Smits, and M. J. A. P. Daemen, "Matrix metalloproteinase inhibition after myocardial infarction: a new approach to prevent heart failure?" Circulation Research, vol. 89, no. 3, pp. 201-210, 2001.

[57] U. Schönbeck, F. Mach, G. K. Sukhova et al., "Regulation of matrix metalloproteinase expression in human vascular smooth muscle cells by T lymphocytes: a role for CD40 signaling in plaque rupture?" Circulation Research, vol. 81, no. 3, pp. 448454, 1997.

[58] Z. Xie, M. Singh, and K. Singh, "Differential regulation of matrix metalloproteinase- 2 and -9 expression and activity in adult rat cardiac fibroblasts in response to interleukin-1 $\beta$," The Journal of Biological Chemistry, vol. 279, no. 38, pp. 39513-39519, 2004.

[59] M. Balasoiu, A. T. Balasoiu, A. E. Stepan et al., "Proatherogenic adipocytokines levels in metabolic syndrome," Romanian Journal of Morphology and Embryology, vol. 55, pp. 29-33, 2014.

[60] S. Shaomei, W. Hongmei, Z. Qing et al., "Subnormal peripheral blood leukocyte counts are related to the lowest prevalence and incidence of metabolic syndrome: Tianjin chronic low-grade systemic inflammation and health (TCLSIH) cohort study," Mediators of Inflammation, vol. 2014, Article ID 412386, 12 pages, 2014, in press. 


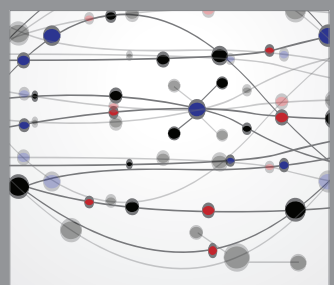

The Scientific World Journal
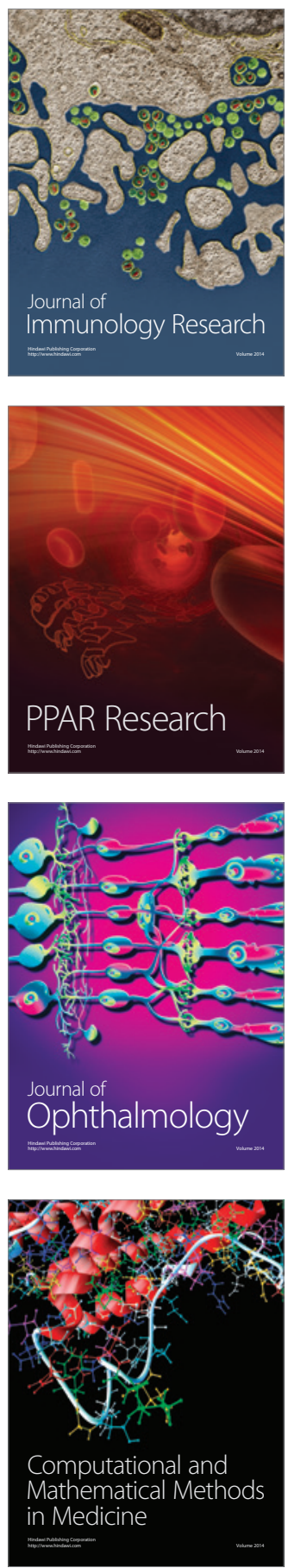

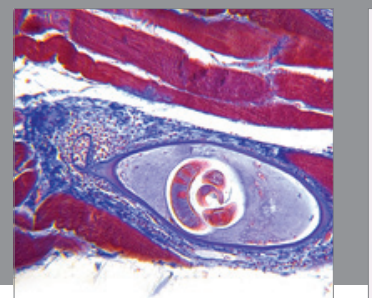

Gastroenterology

Research and Practice
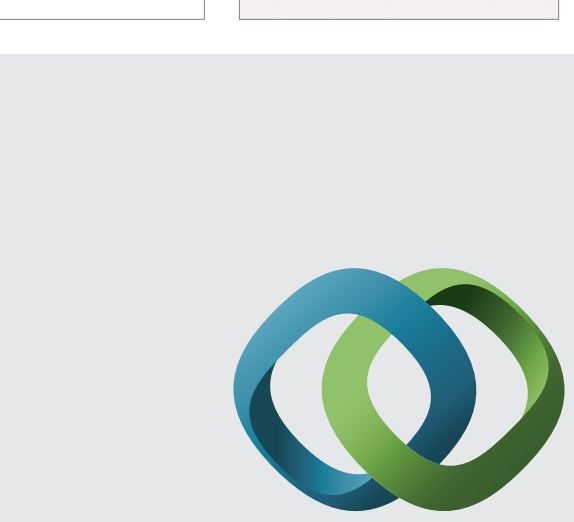

\section{Hindawi}

Submit your manuscripts at

http://www.hindawi.com
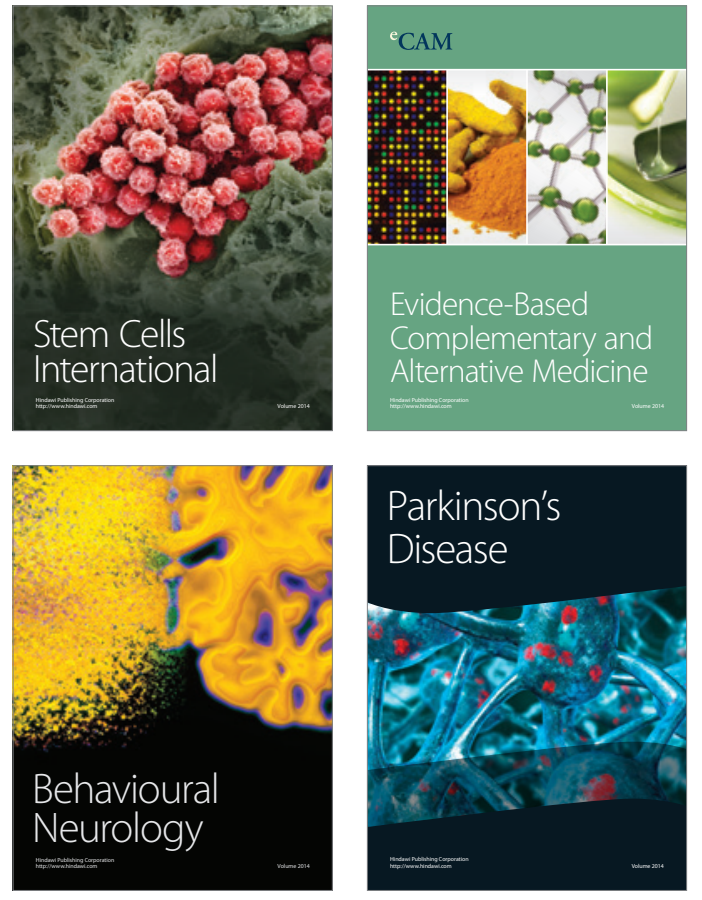
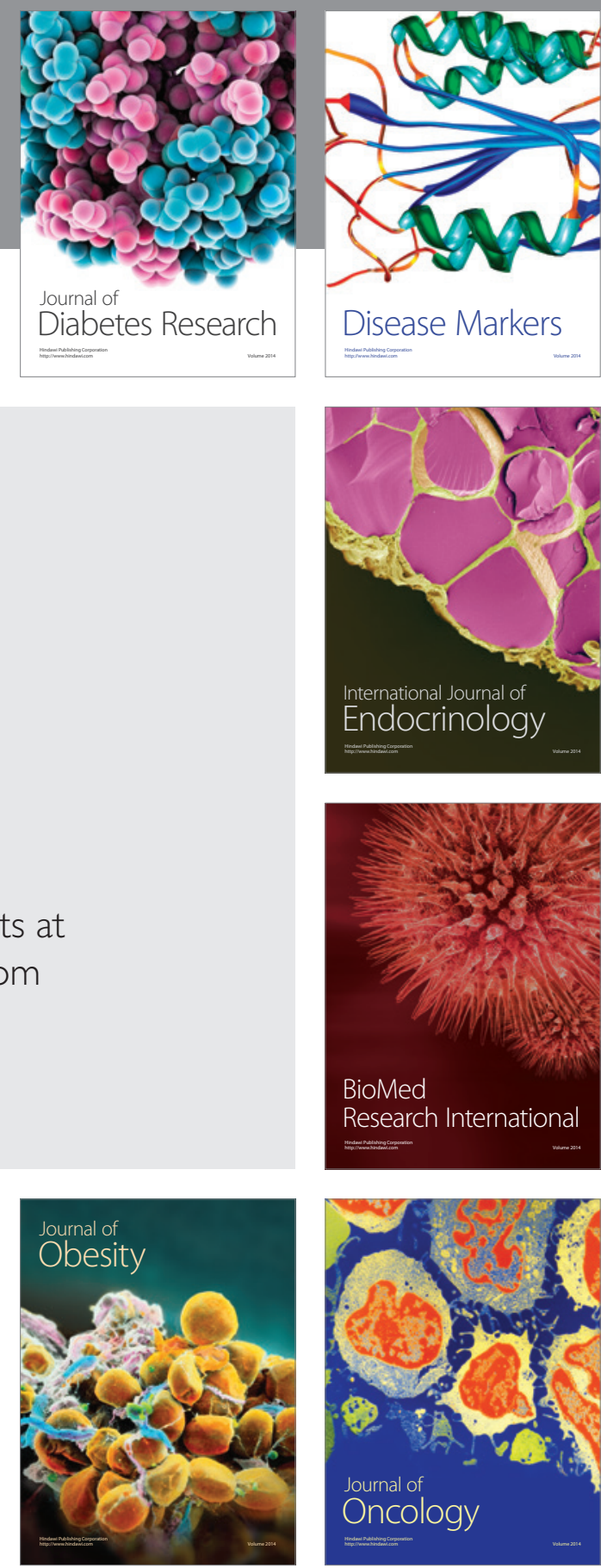

Disease Markers
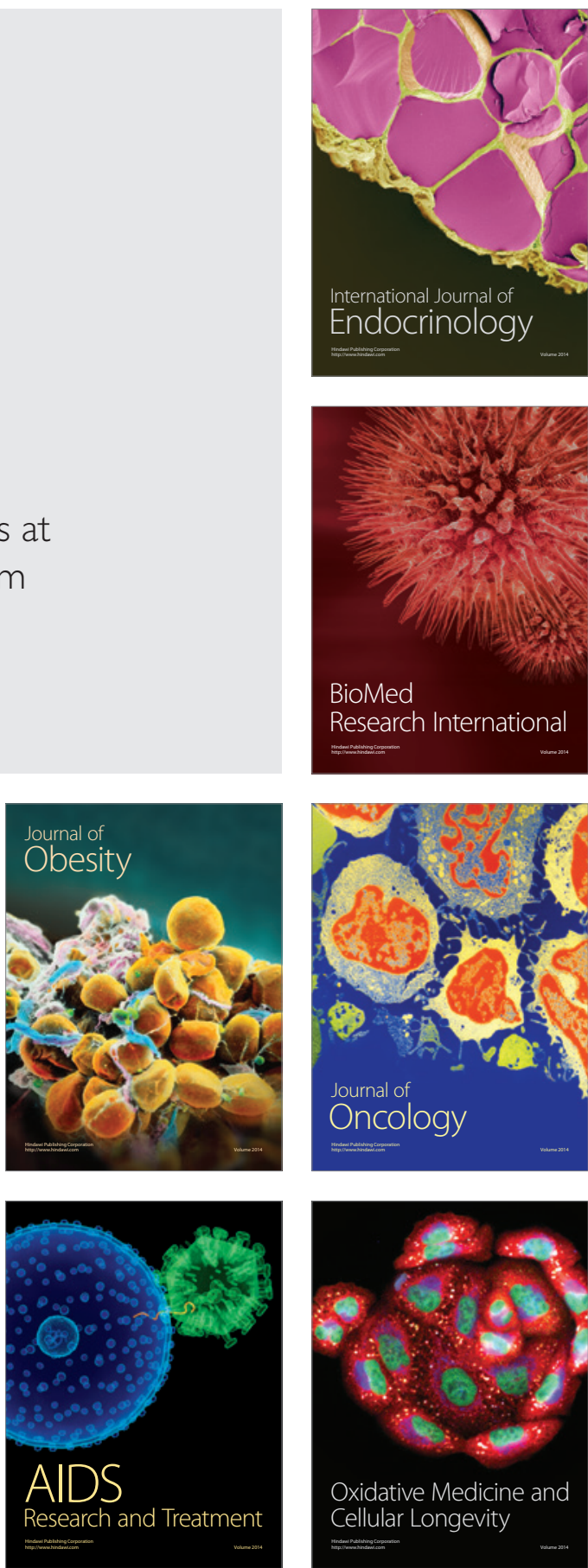